\title{
Simple colorimetric assay for dehalogenation reactivity of nanoscale zero-valent iron using 4-chlorophenol
}

Hwang, Yuhoon; Mines, Paul D.; Jakobsen, Mogens Havsteen; Andersen, Henrik Rasmus

Published in:

Applied Catalysis B: Environmental

Link to article, DOI:

10.1016/j.apcatb.2014.10.059

Publication date:

2015

Link back to DTU Orbit

Citation (APA):

Hwang, Y., Mines, P. D., Jakobsen, M. H., \& Andersen, H. R. (2015). Simple colorimetric assay for dehalogenation reactivity of nanoscale zero-valent iron using 4-chlorophenol. Applied Catalysis B: Environmental, 166-167, 18-24. https://doi.org/10.1016/j.apcatb.2014.10.059

\section{General rights}

Copyright and moral rights for the publications made accessible in the public portal are retained by the authors and/or other copyright owners and it is a condition of accessing publications that users recognise and abide by the legal requirements associated with these rights.

- Users may download and print one copy of any publication from the public portal for the purpose of private study or research.

- You may not further distribute the material or use it for any profit-making activity or commercial gain

- You may freely distribute the URL identifying the publication in the public portal 
Post Print: This is a post print of the manuscript "Simple colorimetric assay for dehalogenation reactivity of nanoscale zero-valent iron using 4-chlorophenol." accepted for publication on the 22/10 2014. The publishers' version is printed in Applied Catalysis B: Environmental and is available at http://dx.doi.org/10.1016/j.apcatb.2014.10.059

\section{Simple colorimetric assay for dehalogenation reactivity of nanoscale zero-valent iron using 4-chlorophenol}

Yuhoon Hwang ${ }^{1}$, Paul D. Mines ${ }^{1}$, Mogens H. Jakobsen ${ }^{2}$, Henrik R. Andersen ${ }^{1 *}$ ${ }^{1}$ Department of Environmental Engineering, Technical University of Denmark, Miljøvej, B113, DK-2800 Kgs. Lyngby, Denmark

${ }^{2}$ Department of Micro- and Nanotechnology, Technical University of Denmark, Ørsteds Plads, B 345E, DK-2800 Kgs. Lyngby, Denmark

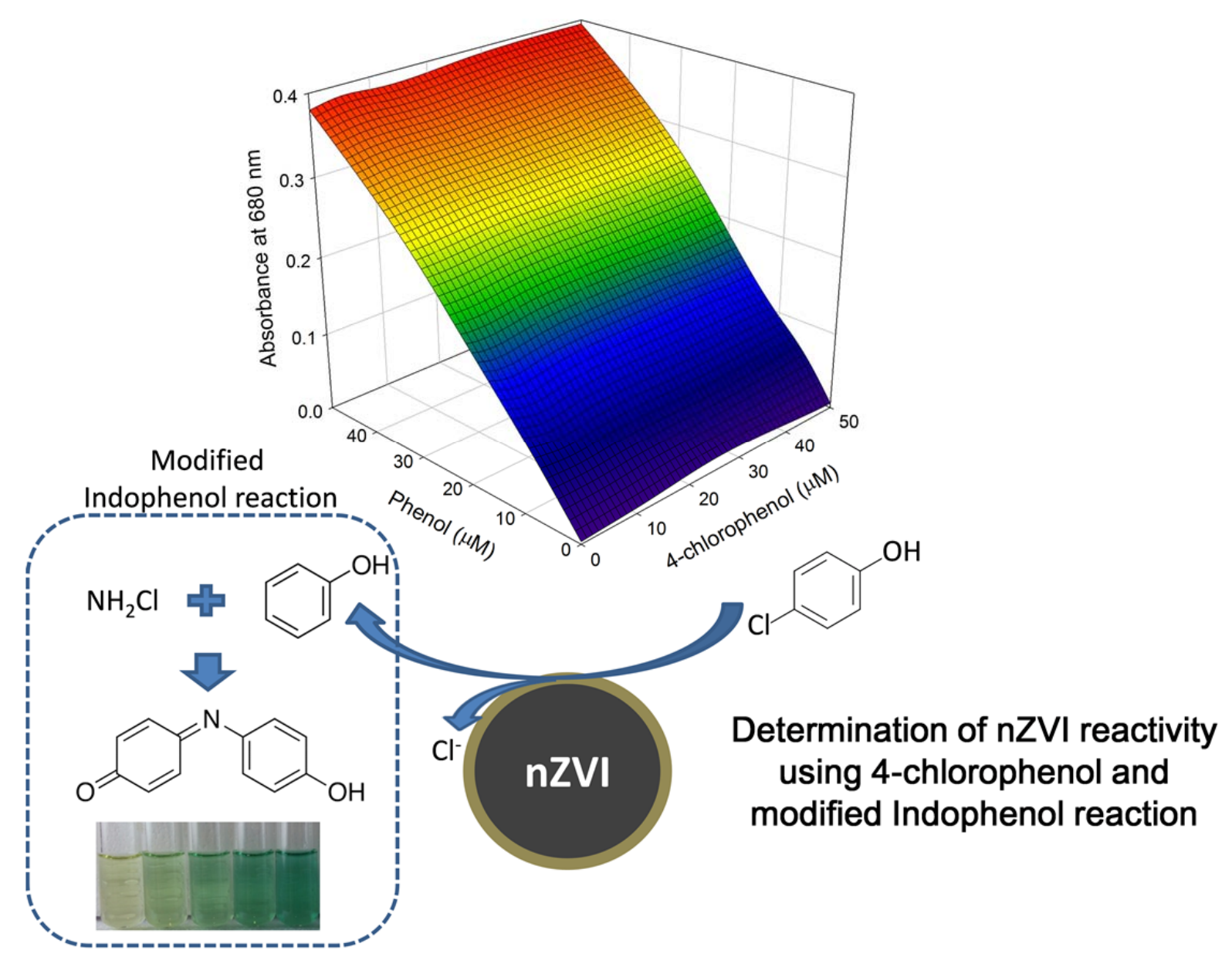

* Corresponding author

Henrik R. Andersen

E-mail:hran@env.dtu.dk

Tel: +45-4525-1583

Fax: +45-4593-2850 


\title{
Highlights
}

- Colorimetric assay developed for reductive de-chlorination based on 4-chlorphenol

- Color development through indophenol formation occur only by the product, phenol

- Low de-chlorination activity of pure nZVI observed, which is improved by nickel addition

- Interference of color reading by iron ions eliminated by sodium carbonate addition

\begin{abstract}
Despite the wide application of nanoscale zero valent iron (nZVI) for the treatment of a plethora of pollutants through reductive reactions, reactivity evaluation of nZVI towards dehalogenation has not been standardized. In this light, it was desired to develop a simple colorimetric assay, for versatile laboratory application, using merely a spectrophotometer for color intensity determination. A modification of the indophenol reaction, which is well known for its use in ammonia detection, is suggested for this color assay. Being that 4chlorophenol can be reduced to phenol by nZVI but cannot react according to the indophenol reaction, as its para-position is blocked; the simple colorimetric assay for reducing reactivity determination of nZVI to organically bound halogens was developed, using 4-chlorophenol as the model substrate that is selectively reduced to phenol by nZVI. The sensitivity and selectivity of the color assay for phenol detection was initially investigated. Since a shift of the peak absorbance was observed at higher concentrations of indophenol formed from phenol, the appropriate concentration range for analysis was determined as $0-50 \mu \mathrm{M}$, with a peak absorbance at $680 \mathrm{~nm}$. The suggested color assay showed superior selectivity toward phenol in the presence of 4-chlorophenol. However, the high concentration of soluble iron ions produced throughout the reaction caused positive interference on absorbance. Addition of $\mathrm{NaCO}_{3}$ for the pre-treatment of samples was suggested to eliminate the effect of residual iron ions and acidity from buffers used in nZVI reactivity tests. Several types of nZVI were investigated with the reaction, including monometallic nZVI and bimetallic nZVIs of $\mathrm{Ni} / \mathrm{Fe}$ and $\mathrm{Cu} / \mathrm{Fe}$; and only $\mathrm{Ni} / \mathrm{Fe}$ particles were able to produce phenol, indicating the reducing reactivity of $\mathrm{Ni}$ to produce atomic hydrogen along with an electron supplied by the core of nZVI. Throughout this study, the 4-chlorophenol based reactivity assay, using the modified indophenol reaction, successfully determined reducing reactivity of nZVI in varied experimental conditions.
\end{abstract}

\section{Keywords}

Nanoscale zero valent iron; 4-chlorophenol; Indophenol reaction; Dehalogenation reactivity; Colorimetric assay 


\section{INTRODUCTION}

Zero valent iron (ZVI), by utilizing reductive reaction mechanisms, has been applied in the removal of a wide variety of pollutants, especially halogenated organics, including chlorinated hydrocarbons, chlorinated phenols, polychlorinated biphenyls (PCBs), etc. [1]. In particular, it has been found that nanoscale ZVI (nZVI) exhibited much higher activity for dehalogenation than commercially available micro-iron powder, due to the difference in specific surface area [2]. Moreover, the further enhancement of nZVI reactivity has been intensively investigated. A wide range of stabilizers, e.g. surfactant [3], sodium carboxymethyl cellulose [4], starch [5], and guar gum [6], have been applied to prevent aggregation of nZVI, although this can lead to a decrease in actual surface area available for reaction [7]. The application of a second metal is another approach for enhancement of nZVI reactivity. In bimetallic materials, the primary metal, having a lower standard redox potential, Fe, acts as an electron donor to reduce the contaminants; while the secondary metal $(\mathrm{Pd}, \mathrm{Pt}, \mathrm{Ag}, \mathrm{Ni}, \mathrm{Cu}$, etc.), acting as a catalyst and having a high standard redox potential, promotes the reactivity via hydrogenation and accelerates corrosion [8-10].

However, the evaluation of nZVI reactivity towards dehalogenation has not yet been standardized in previous studies. The use of advanced chromatographic techniques has mostly been applied to determine the parent compound and subsequent degradation products $[11,12]$. These techniques are powerful tools to analyze the compounds both qualitatively and quantitatively. Nevertheless, it generally requires long analysis times and complicated set-ups. In this light, a simple color assay for use in laboratories, requiring only a basic spectrophotometer, for determining color intensity should be developed.

Chlorinated phenols, which are broadly used as wood preservatives, anti-rust agents, and pesticides, have become an note-worthy contaminant in the environment [13], being that most of them are toxic, carcinogenic, and intractable [14]. Due to the aryl structure and presence of the chlorine atom, chlorinated phenols are exceptionally recalcitrant towards chemical reactions aimed at their reduction [15]. In the last decade, application of ZVI for reduction of chlorophenols has been extensively studied [8, 15-18]. Chlorophenol can be reduced to phenol via dehalogenation, driven from electron transfer, and it is generally accepted that phenol is the only product during this process $[16,17]$.

The indophenol reaction is the name given to the reaction of monochloramine and a phenol, which, under suitable conditions, results in the formation of a blue indophenol dye, which can be determined spectrophotometrically [19]. This reaction is highly specific for ammonia, and in the presence of a suitable catalyst, extremely high sensitivity is attainable. The reaction mechanism, as it's understood, is outlined below in Eqs. 1-3 [20]

$$
\mathrm{NH}_{3}+\mathrm{NaOCl} \longrightarrow \mathrm{NH}_{2} \mathrm{Cl}+\mathrm{NaOH}
$$

(Eq. 1)

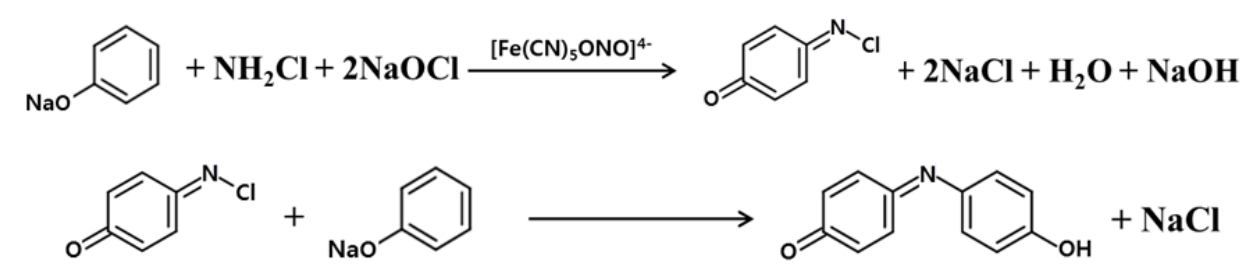

(Eq. 2)

(Eq. 3)

The produced monochloramine in Eq. 1 reacts with the para position of phenol, and N-chloro-p-hydroxybenzoquinone monoamine is produced. This intermediate reacts with phenolate to produce a blue colored indophenol. Since the para position of phenol is involved in this reaction, it is generally accepted that only phenols with un-substituted parapositions can make this reaction [19]. Therefore, it can be hypothesized that phenols with a substituted para position will not be detected by this reaction; whereas the reduction product of it, phenol, will produce color. Because it is known that para-chlorophenol (4-chlorophenol) is able to be reduced to phenol by the reaction with nZVI; in this study, 4-chlorophenol is chosen as a target compound for the development of a color assay.

Herein, the simple colorimetric assay for reducing reactivity determination of nZVI to organically bound halogens was developed, using 4-chlorophenol as the model substrate that is selectively reduced to phenol by nZVI. Firstly, the sensitivity of the color assay was optimized for phenol quantification. Secondly, the selectivity of the color assay towards phenol, in the presence of 4-chlorophenol, was investigated to test the feasibility of the assay. Several types of nZVI and bimetallic nZVI $(\mathrm{Ni} / \mathrm{Fe}, \mathrm{Cu} / \mathrm{Fe})$ were tested for degradation of 4-chlorophenol to phenol; in order to demonstrate the applicability of the method and the feasibility to distinguish reducing reactivity. The matrix effect, namely $\mathrm{pH}$ and residual iron ions concentration, was investigated and carbonate addition is applied to eliminate any interferences. Based on the overall results of bimetallic nZVI reactivity and the selectivity of the color assay, a simple and effective assay to determine reactivity of nZVI is suggested. 


\section{METHODS}

\subsection{Chemicals}

Ferrous sulfate heptahydrate ( $>99 \%$, Fluka), sodium borohydride ( $>98 \%$, Sigma-Aldrich), copper sulfate pentahydrate $(>99 \%$, Fluka) and nickel sulfate hexahydrate (>99\%, Sigma-Aldrich), ethanol ( $>99.9 \%$, Sigma-Aldrich) were used for nZVI synthesis. Phenol ( $>99 \%$, Fluka), 4-chlorophenol ( $>98 \%$, Merck), sodium hypochlorite solution (10\%, Fluka), ammonium chloride ( $>99.5 \%$, Sigma-Aldrich), sodium nitroprussid ( $>99 \%$, Merck) were used for the modified indophenol reaction. Hydrochloric acid (37\%, Sigma-Aldrich), sodium hydroxide ( $>98 \%$, Sigma-Aldrich), sodium citrate $(>98 \%$, Sigma-Aldrich), citric acid $(>99.8 \%$, Fluka), and acetate $(>99.8 \%$, Sigma-Aldrich) were used for $\mathrm{pH}$ adjustment. Ferric chloride hexahydrate ( $>98 \%$, Sigma-Aldrich) was used for investigating effect of residual iron ions in the sample. Sodium carbonate ( $>99 \%$, Sigma-Aldrich) was used for sample pretreatment. Unless otherwise stated, all of the chemicals were used as received from the supplier. All solutions were prepared using degassed deionized water (DDIW) by purging with nitrogen gas for 3 hours.

\subsection{Reagents and optimized assay procedure}

Typical reaction conditions for ammonium measurement using the indophenol reaction had ammonium as the limiting reagent, and excess amounts of phenol and hypochlorite were applied to ensure all ammonium forms indophenol, catalyzed by sodium nitroprusside. In this study, phenol was chosen as the limiting reagent, in order to have the color development dependent on the concentration of phenol.

In this study, reagent $\mathrm{A}$, hypochlorite- $\mathrm{NaOH}$ solution, and reagent $\mathrm{B}$, ammonium-sodium nitroprusside solution, were prepared for the suggested color assay. Reagent A was prepared by diluting $1 \mathrm{~mL}$ of $10 \%$ hypochlorite solution and 66 $\mathrm{mL}$ of $0.5 \mathrm{M} \mathrm{NaOH}$ solution to $100 \mathrm{~mL}$ with DDIW. Reagent B was prepared as $1250 \mathrm{mg}-\mathrm{N} / \mathrm{L}$ of ammonium chloride (4.78 $\left.\mathrm{g} \mathrm{NH}_{4} \mathrm{Cl} / \mathrm{L}\right)$ and $0.3 \mathrm{~g} / \mathrm{L}$ of sodium nitroprusside in DDIW. A drop of hydrochloric acid was added to minimize ammonia stripping to the headspace in the reaction vessel. Reagent $\mathrm{C}$ was prepared by dissolving $106 \mathrm{~g} / \mathrm{L} \mathrm{Na} \mathrm{CO}_{3}$ to make a $1 \mathrm{M}$ solution. Reagent $\mathrm{C}$ is used to neutralize any acidic buffer that might be used in the experiments with $\mathrm{nZVI}$ reactivity and to precipitate residual soluble iron ion $\left(\mathrm{Fe}^{2+}\right.$ or $\left.\mathrm{Fe}^{3+}\right)$ produced throughout reaction, in order to remove interferences with the color reading.

The following procedure was used to quantify phenol in the reaction mixture: $5 \mathrm{~mL}$ of homogenized samples were pretreated by $250 \mu \mathrm{L}$ of carbonate solution (reagent $\mathrm{C}$ ) to neutralize the acidic buffer and to precipitate interfering iron ions. Produced iron carbonate was well precipitated in 30 minutes, and the supernatant was taken for phenol analysis. Equal volumes of reagents $\mathrm{A}$ and $\mathrm{B}$ were mixed to make the reagent $\mathrm{AB}$, prior to sample addition. Then, $2.3 \mathrm{~mL}$ of diluted sample, having an expected phenol concentration range of $0-50 \mu \mathrm{M}$, was transferred into a tube, and $0.2 \mathrm{~mL}$ of reagent $\mathrm{AB}$ was added to the diluted sample. The mixture was gently shaken and allowed to react in the dark for 2 hours and subsequently quantified with a photometer at $680 \mathrm{~nm}$ in $1.0 \mathrm{~cm}$ polycarbonate cuvette. Depending on the desired precision of quantification, a 5 point calibration curve (Blank, 5, 10, 25 and $50 \mu \mathrm{M}$ of phenol) was obtained in parallel. If a high precision isn't required (kinetic or competitive studies), quantification is performed using the determined calibration curve: $[$ phenol, $\mu \mathrm{M}]=\left(\right.$ Abs- $\left.1.43 \cdot 10^{-2} \mathrm{~cm}^{-1}\right) /\left(7,62 \cdot 10^{-3} \mathrm{~cm}\right)$.

\subsection{Sensitivity and selectivity of color assay for phenol detection}

In order to investigate the sensitivity of the color assay suggested in this study, the adsorption spectra of phenol and 4chlorophenol solution, in the concentration range of $0-2000 \mu \mathrm{M}$, was monitored. The color assay's selectivity towards phenol was investigated using a mixture of phenol and 4-chlorophenol, in the concentration range of 0 to $50 \mu \mathrm{M}$. The mixture composition was designed as a full factorial design. Adsorption spectra of reacted samples were monitored using a UV-Vis spectrophotometer (Cary 50, Agilent Technologies Inc., USA), and the absorbance at $680 \mathrm{~nm}$ was chosen as the response variable. Design-Expert 7.0.0 (Stat-Ease, Inc. USA) was used for analysis of variance (ANOVA), mathematical regression models, and to plot response surfaces.

The effects of $\mathrm{pH}$ and residual iron concentration in the sample on the color assay were also investigated. The phenol concentration was fixed at $20 \mu \mathrm{M}$. Iron concentration was controlled by ferric chloride stock solution, and the sample $\mathrm{pH}$ was adjusted using $0.1 \mathrm{M}$ hydrochloric acid and $0.1 \mathrm{M}$ sodium hydroxide. Additionally, the total iron concentration was monitored by an atomic absorption spectrometer (AAnalyst 200, PerkinElmer, USA).

\subsection{Reduction of 4-chlorophenol by monometallic and bimetallic nZVI \\ 2.4.1 Preparation of monometallic and bimetallic nZVIs}

In this study, the mild chemical reduction of metal salts in the solution phase was used to prepare nZVI, as stated in previous research [21]:

$$
2 \mathrm{Fe}^{2+}+\mathrm{BH}_{4}^{-}+3 \mathrm{H}_{2} \mathrm{O} \rightarrow 2 \mathrm{Fe}^{0}+\mathrm{H}_{2} \mathrm{BO}_{3}^{-}+4 \mathrm{H}^{+}+2 \mathrm{H}_{2} \quad \text { (Eq. 4) }
$$


The concentrations of ferrous $\left(\mathrm{Fe}^{2+}\right)$ solution and sodium borohydride solution were 35.8 and $89.6 \mathrm{mM}$, respectively. Ferrous sulfate and sodium borohydride solutions were introduced via peristaltic pump with a constant delivery rate of 5 $\mathrm{mL} / \mathrm{min}$. Collection of nZVI was performed via centrifugation (4500 rpm, $5 \mathrm{~min}$, Heraeus Multifuge X1, Thermo Fisher Scientific Inc., USA) of the solution, and the collected particles were then washed twice with DDIW. In order to achieve a dry nZVI powder, the solution was washed with ethanol was and subsequently dried in an anaerobic chamber $\left(\mathrm{N}_{2}: \mathrm{H}_{2}=95: 5\right.$, Coy laboratory products, USA).

Bimetallic particles were prepared via chemical reduction, similar as with nZVI preparation. The co-reduction of FeSO and $\mathrm{NiSO}_{4}$ was performed, as described by Zhang et al. [8]. The detailed preparation procedure was the same as with the monometallic nZVI preparation, except that a mixture of ferrous sulfate and nickel sulfate was reduced by sodium borohydride. Being that nickel has a higher standard redox potential, the nickel $\left(\mathrm{Ni}^{2+}\right)$ ion in solution will take the form of reduced metallic nickel, prior to iron reduction. Therefore, the nickel will be located in the core of the resultant bimetallic Ni/Fe particles. In order to ensure that the secondary metal ends up on the surface of the nZVI, a step-wise reduction of metal salts was conducted. The bimetallic nZVIs were prepared by mixing the secondary metal solution $\left(\mathrm{CuSO}_{4}, \mathrm{NiSO}_{4}\right)$ with freshly prepared nZVI particles [22, 23]. After 5 min of redox reaction between the second metal and $\mathrm{nZVI}$, the resulting $\mathrm{Ni} / \mathrm{Fe}$ and $\mathrm{Cu} / \mathrm{Fe}$ bimetallic particles were washed twice with DDIW. In all cases, the amount of second metal was calculated to be $5 \mathrm{wt} \%$ of Fe weight.

\subsubsection{4-chlorophenol dechlorination by different nZVI}

Batch tests for 4-chlorophenol degradation by nZVI were conducted in a 50-mL glass serum bottle. The bottle was initially filled with 4-chlorophenol stock solutions, and prepared nZVI was added to the bottles to initiate the reaction. The nZVIs tested in this study were monometallic nZVI (in both dried and slurry form), co-reduced Ni/Fe, stepwisereduced $\mathrm{Ni} / \mathrm{Fe}$, and $\mathrm{Cu} / \mathrm{Fe}$. Solution $\mathrm{pH}$ was controlled by either adjustment of initial $\mathrm{pH}$ or buffering with citrate or acetate. The nominal concentrations of 4-chlorophenol, buffer, and nZVI were $500 \mu \mathrm{M}, 10 \mathrm{mM}$, and 2 g/L, respectively. The headspace of the bottle was purged with nitrogen gas and securely capped with a PTFE/silicon septum and aluminum crimp seal. The bottle was mixed on a shaker at $125 \mathrm{rpm}$. Samples of $5 \mathrm{~mL}$ were taken periodically and filtered with $0.45 \mu \mathrm{m}$ syringe filters. The phenol concentration in the sample was measured as described in section 2.2 .

\section{RESULTS AND DISCUSSION}

\subsection{Sensitivity and selectivity of color assay for phenol detection}

The suggested color assay, i.e. the modified indophenol reaction, was tested for detection of both phenol and 4chlorophenol in the concentration range of $0-2000 \mu \mathrm{M}$. The adsorption spectra of the color product by phenol are detailed in Figure 1 (a). The shift of peak absorbance was observed at the concentration range of $100-400 \mu \mathrm{M}$. The peak absorbance in concentrations lower than $100 \mu \mathrm{M}$ was consistent at $680 \pm 7 \mathrm{~nm}$, while the peak absorbance in concentrations higher than $400 \mu \mathrm{M}$ was $640 \pm 2 \mathrm{~nm}$. In this sense, the appropriate concentration range for analysis was determined as $0-50 \mu \mathrm{M}$, since linearity was not maintained after $50 \mu \mathrm{M}$. The standard curve of absorbance at $680 \mathrm{~nm}$ versus phenol concentration is plotted in Figure 2. The slope of standard curve was determined as $7.62 \times 10^{-3}$, with a $\mathrm{R}^{2}$ value of 0.998 .

The color development by 4-chlorophenol is much lower than phenol, as is detailed in Figure 1 (b), which elucidated the higher sensitivity of color assay toward phenol. The slope of standard curve was determined as $4.00 \times 10^{-4}$, with a $\mathrm{R}^{2}$ value of 0.990 . The slight color development from 4-chlorophenol might be attributed to the non-para substituted phenol, due to the impurities in the 4-chlorophenol, which has a purity of $>98 \%$.

(a)

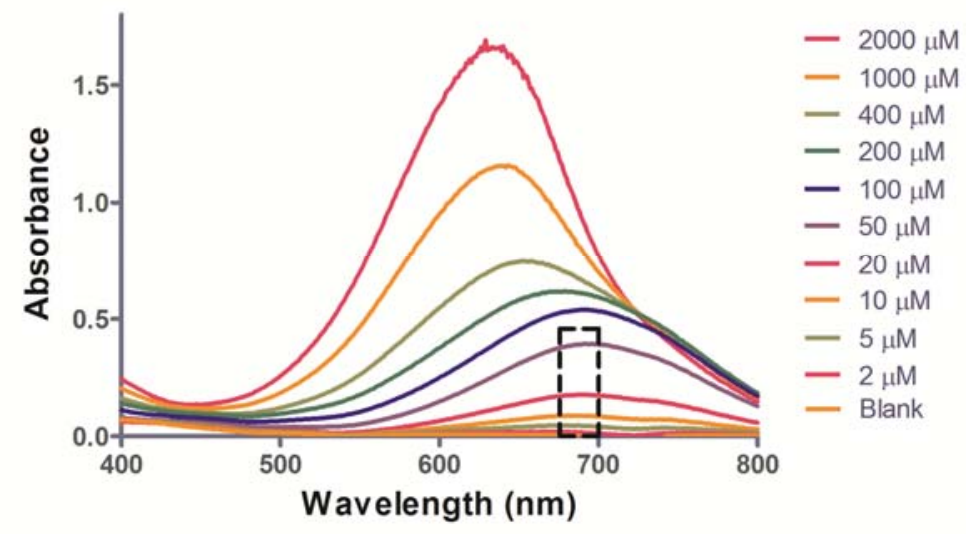


(b)

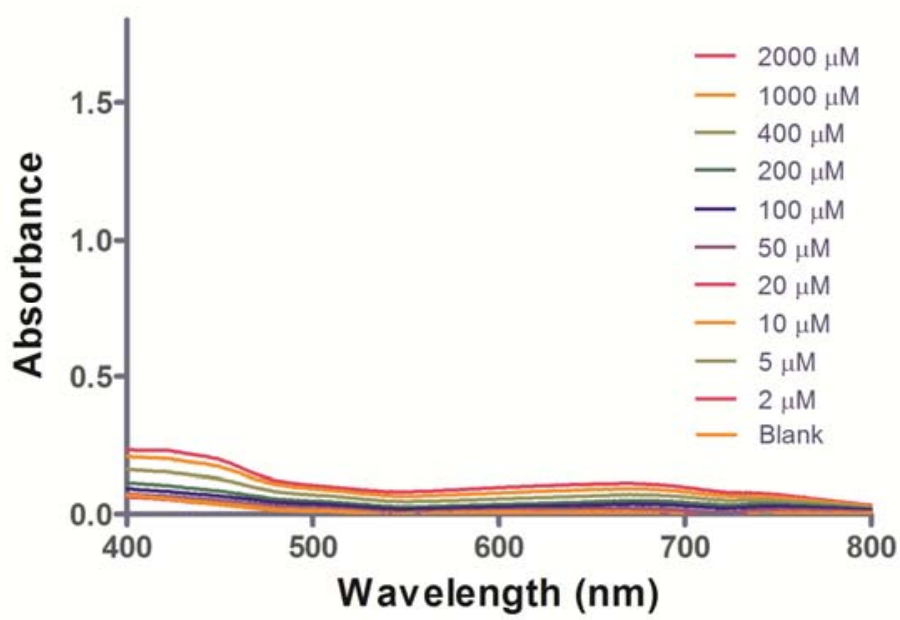

Fig. 1. Spectra evolution with different concentrations ( $\mu \mathrm{M})$ of (a) phenol and (b) 4-chlorophenol after reaction with $\mathrm{NH}_{2} \mathrm{Cl}$ (reagent $\left.\mathrm{AB}\right)$.

The selectivity of the color assay towards phenol detection in the presence of 4-chlorophenol was evaluated. The concentrations of phenol and 4-chlorophenol were adjusted to $0,5,10,25$, and $50 \mu \mathrm{M}$, the same as in the previous standard curve; and the full factorial design was applied to investigate the assay's selectivity. Standard curves, having different concentrations of 4-chlorophenol, are presented in Figure 2. The slope of the standard curves were $7.61 \pm 0.08$ $\times 10^{-3}$, and the slope did not show a positive correlation with added 4-chlorophenol. In this sense, it was demonstrated that the selectivity of the color assay adequately distinguished phenol in the presence of 4-chlorophenol.

The response surface obtained from full factorial design is presented in Figure S1. The derived equation is given in Eq. 5.

Absorbance at $680 \mathrm{~nm}=7.56 \times 10^{-3} \cdot[$ Phenol $]+1.19 \times 10^{-4} \cdot[4$-chlorophenol $]+3.25 \times 10^{-6} \cdot[$ Phenol $] \cdot[4$-chlorophenol $]+$ $1.21 \times 10^{-2}\left(\mathrm{R}^{2}=0.9960\right) \quad$ (Eq. 5)

Absorbance at $680 \mathrm{~nm}=7.62 \times 10^{-3} \cdot[\mathrm{Phenol}]+1.43 \times 10^{-2}\left(\mathrm{R}^{2}=0.9954\right) \quad$ (Eq. 6)

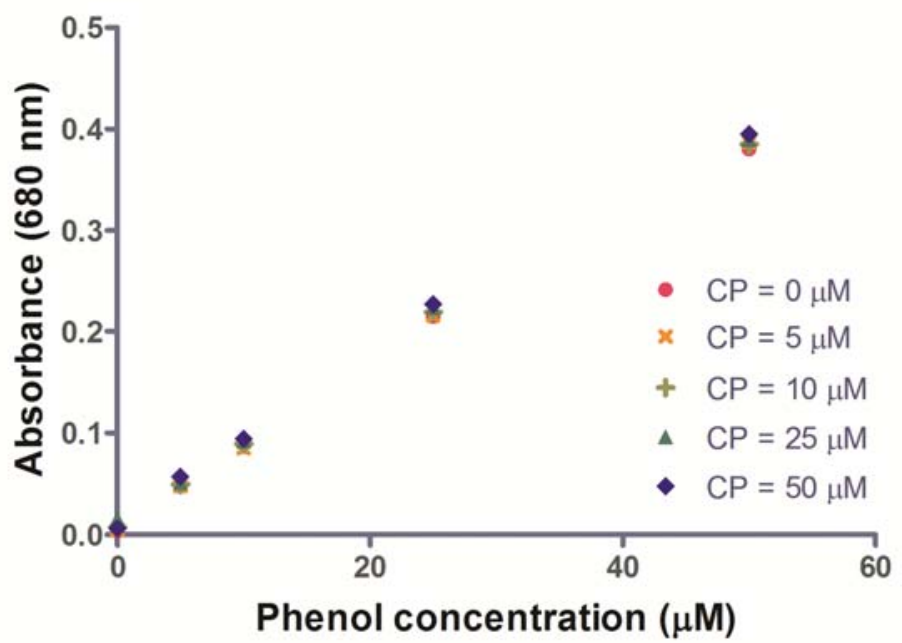

Fig. 2. Standard curve for phenol $(0-50 \mu M)$ after reaction with $\mathrm{NH}_{2} \mathrm{Cl}$ in the presence of $0,5,10,25$, and $50 \mu \mathrm{M}$ 4-chlorophenol.

The $\mathrm{p}$-value of the model is $<0.0001$, which indicates that the derived equation is significant. The $\mathrm{p}$-value of model terms, [Phenol], [4-chlorophenol], and [Phenol] [4-chlorophenol] are $<0.0001,0.1008$ and 0.5830, respectively. Since model terms having p-value greater than 0.1000 indicates insignificant model terms, the term [Phenol] is the only significant model term in the equation. Therefore, the model can be rearranged as Eq. 6, and the slope is in the range of the values obtained using the individual standard curves with various 4-chlorophenol concentrations. Therefore, it can 
be concluded that the indophenol reaction used in this study exhibits high selectivity towards phenol, in the presence of 4-chlorophenol.

\subsection{Reducing reactivity of nZVI for reduction of 4-chlorophenol to phenol}

The reactivity of several nZVIs was evaluated through a 4-chlorophenol reduction test. Dried nZVI powder was applied under buffered and un-buffered conditions, with initial pH's of 3, 5, and 7. Phenol production was not detected in any sample. The slurry form of nZVI, i.e. without drying, was also tested under the same conditions as with dried nZVI powder. However, no phenol production was detected in any sample.

Bimetallic nZVI particles have been reported to have superior reactivity for 4-chlorophenol reduction compared to monometallic nZVI [8]. In this study, co-reduction of both metal precursors and stepwise-reduction of metal precursors were tested. Figure S2 presents the phenol concentration in the case of co-reduction. Since the initial concentration of 4-chlorophenol was $500 \mu \mathrm{M}$, the theoretical maximum of produced phenol would be $500 \mu \mathrm{M}$ as explained by Li et al. [15]. The produced phenol after 2 hours of reaction time was $30.5 \%$ of the theoretical maximum. Therefore, it is determined that certain types of nZVI, specifically Ni/Fe prepared in this study, have an affinity for reduction reactivity with 4-chlorophenol, which can be detected by the suggested method.

Being that the standard redox potential of the second metal, nickel in this case, is higher than iron; it could be assumed that nickel would mainly be located in the core of bimetallic particles as it reduces first. Given this fact, the stepwisereduction of iron and nickel was performed to position nickel on the surface of the nZVI, which can subsequently promote the surface reaction of nickel. Figure 3 (a) presents the phenol concentration through 4-chlorophenol reduction by monometallic and stepwise-reduced bimetallic Ni/Fe and $\mathrm{Cu} / \mathrm{Fe}$. As is illustrated in Figure 3 (a), the Ni/Fe exhibits an ability to produce phenol, whereas $\mathrm{Cu} / \mathrm{Fe}$ and monometallic $\mathrm{Fe}$ exhibit limited production of phenol.

(a)

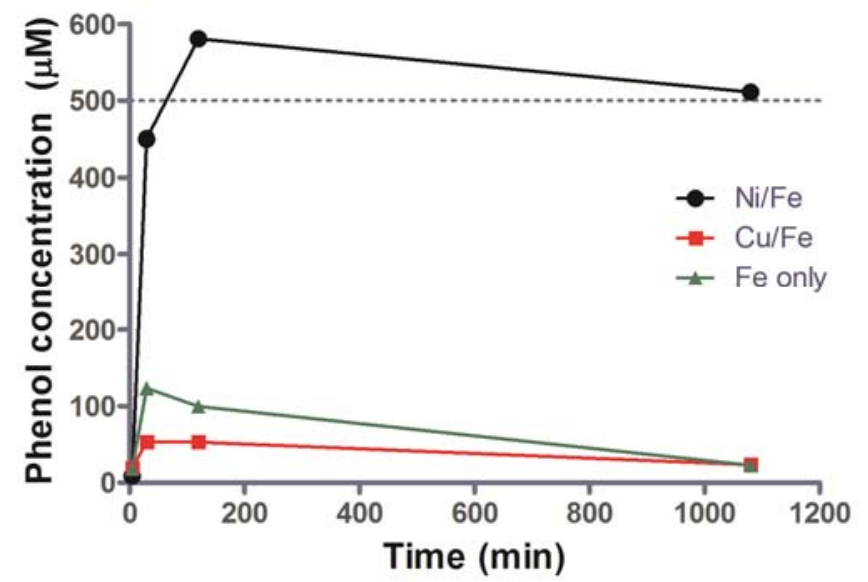

(b)

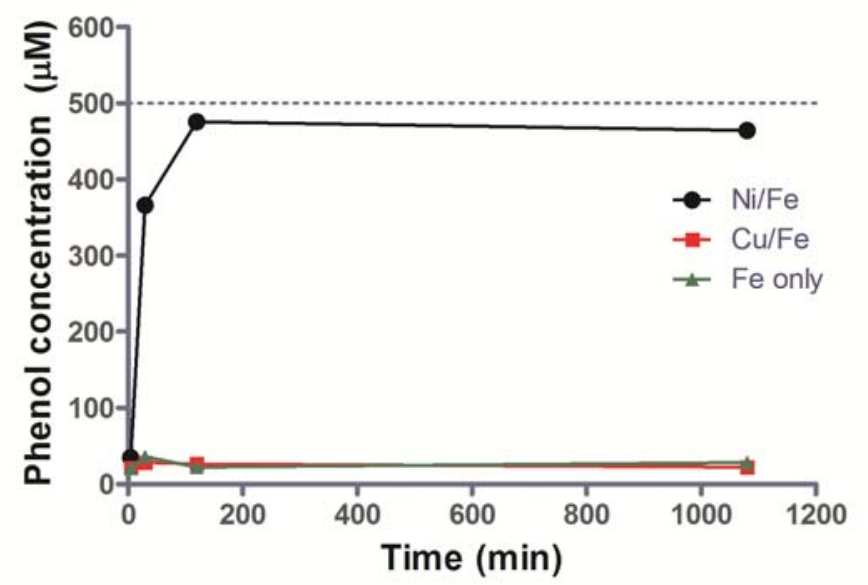

Fig. 3. Effect of the second metal on the 4-chlorophenol reduction by nZVI (a) without sample pretreatment, and (b) with sample pretreatment. Dotted line indicate theoretical yield. 
In general, the enhancement of dehalogenation activity by a bimetallic system would be understood as a combination of galvanic effects and surface properties of the second metal. A higher standard redox potential of the second metal would develop a galvanic cell where iron corrosion accelerates. In addition, some dopant metals, e.g., Pd, are also well-known hydrogenation catalysts [24]. In fact, the enhanced reactivity of $\mathrm{Pd} / \mathrm{Fe}$ nanoparticles for dehalogenation hydrogenation of organic contaminants has been previously well reported [9, 25]. Hydrogenation occurring on the surface of the second metal is outlined in reactions Eqs. 7-9 [26]. The second metal can enhance the formation of active hydrogen on the particle surface (Eq. 8) and the reactive hydrogen generation depends on the absorption capacity of the second metal [10]. Generation of different degradation products in different bimetallic systems has been previously reported and was explained as the difference in the affinity of the contaminant on the metal $[22,27]$.

$$
\begin{gathered}
\mathrm{Fe} \rightarrow \mathrm{Fe}^{2+}+2 \mathrm{e}^{-} \quad \text { (Eq. 7) } \\
2 \mathrm{H}^{+}+2 \mathrm{e}^{-} \rightarrow 2 \mathrm{H}^{*} \quad \text { (Eq. 8) } \\
\mathrm{RX}+2 \mathrm{H}^{*} \rightarrow \mathrm{RH}+\mathrm{HX}
\end{gathered}
$$

The results outlined that nickel has the ability to reduce 4-chlorophenol, as described in Eqs. 7-9. It was previously reported that $\mathrm{Ni}$ is a suitable second metal for 4-chlorophenol degradation, which can provide reducing reactivity for atomic hydrogen production $[8,17]$. The higher catalytic reactivity of Ni was also reported in several studies on 1,1,1trichloroethane reduction [25] and hydrogen generation in the reaction with water [28]. Therefore, it was detailed that the modified indophenol reaction coupled with 4-chlorophenol, as suggested in this study, can selectively determine reactive $\mathrm{nZVI}$ that can reduce 4-chlorophenol.

However, the phenol concentrations in the Ni/Fe samples were higher than the theoretical maximum. Furthermore, some development of color was observed in the case of $\mathrm{Cu} / \mathrm{Fe}$ and monometallic $\mathrm{Fe}$, as well. It could be explained with adsorption spectra in the range of $400-800 \mathrm{~nm}$, as is detailed in Figure 4 (a). Immediately after reagent addition, precipitates, as well as a strong yellow color in the solution, were noticed; and, consequently interfered with the absorbance measurement at $680 \mathrm{~nm}$, which was used for the assay. As the sample taken after 5 minutes of reaction time did not show significant color development by interference, it was hypothesized that the changing of $\mathrm{pH}$ or residual soluble iron ions in the sample could bring interference on the suggested color assay.

\subsection{Sample pretreatment using carbonate to minimize interference from residual iron ions 3.3.1 Effect of $\mathrm{pH}$ and residual iron ions on the phenol determination}

In order to investigate the interference caused by the sample matrix, the effect of $\mathrm{pH}$ and residual iron ions on the color development were evaluated. Plotted in Figure S3 (a), the color development is stable in the pH range of 2.3 through 11, with $20 \mu \mathrm{M}$ of phenol solution. The absorbance at $680 \mathrm{~nm}$ was measured to be $0.1736 \pm 0.0008$, and could be explained by the presence of a sufficient amount of alkali in the reagent. When the reagent is mixed with the sample, the total concentration of sodium hydroxide is $13.2 \mathrm{mM}$, enough to bring the solution to a basic condition. Searle [19] previously reported that the indophenol assay was stable in basic $\mathrm{pH}$ conditions, with an optimum $\mathrm{pH}$ range of $10.4-13.1$. Therefore, it was clear that the effect of $\mathrm{pH}$ could be minimized by supplying a sufficient amount of alkali, depending on the buffer used in the reactivity test.

On the other hand, the clear positive interference from residual iron ions was observed, and is detailed in Figure 4 (b). At concentrations up to $100 \mathrm{mg} / \mathrm{L}$ of ferric ion $\left(\mathrm{Fe}^{3+}\right)$, the measured absorbance was stable; however, the interference drastically increased, which can be observed in Figure S4. Due to the development of color and turbidity by soluble iron, the absorbance measurement at the peak representing phenol was interfered. The iron concentration having significant interference corresponded with the measured iron concentration in samples from the 4-chlorophenol reduction test $(192.8 \pm 9.7 \mathrm{mg} / \mathrm{L})$. Some metals were reported to have interference on the indophenol reaction, if present in sufficient amounts [19]; in particular, iron was reported as having a positive interference on the indophenol reaction [27]. Therefore, it was concluded that sample pretreatment to minimize residual iron ions was required, in order to develop a suitable color assay for nZVI reactivity determination.

\subsubsection{Performance of sample pre-treatment by carbonate for residual iron ions removal}

Sample pretreatment with carbonate solution was used to remove residual iron ions in the sample, by adding $250 \mu \mathrm{L}$ of $1 \mathrm{M} \mathrm{Na}_{2} \mathrm{CO}_{3}$ solution to $5 \mathrm{~mL}$ of sample. Sample color changed from a greenish yellow to a dark green, indicating the formation of iron carbonate. The produced iron carbonate precipitates in the bottom of the test tube; resultantly, a clear supernatant could be obtained after 30 minutes. 
(a)

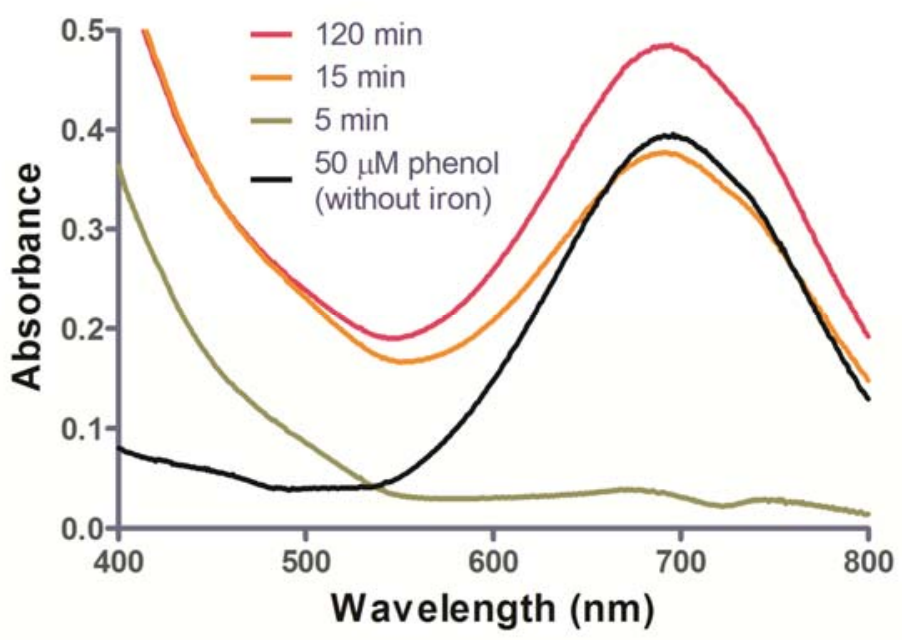

(b)

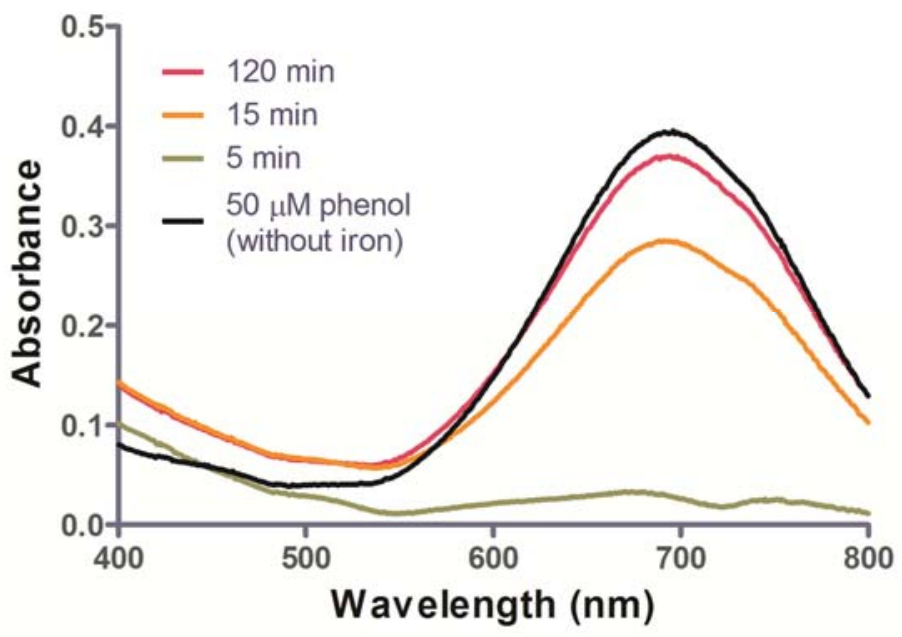

Fig. 4. Spectra change by sample pretreatment using $\mathrm{Na}_{2} \mathrm{CO}_{3}$ (Reagent $\mathrm{C}$ ) (a) without (b) with addition of $\mathrm{Na}_{2} \mathrm{CO}_{3}$.

Figure 4 illustrates the changes of spectra by this pre-treatment, and a positive bias with the absorbance at $680 \mathrm{~nm}$ could be observed in the untreated sample. On the other hand, a stable baseline could be achieved by the suggested pretreatment. Referentially, the spectrum of the $50 \mu \mathrm{M}$ phenol solution is also illustrated in Figure 4 (b). The similar trend of a baseline confirmed the effectiveness of pre-treatment for residual iron removal.

An additional experiment was performed in order to investigate the interference of buffers on the color assay. Commonly, both buffered and un-buffered conditions, have been applied in studies of nZVI reactivity. Buffered conditions have been used for ensuring a stable $\mathrm{pH}$ condition during the reaction [9], while un-buffered conditions have also been frequently applied, due to the ease of reaction control [19]. However, each condition brought a considerably different nature of resultant sample, in terms of buffering capacity, soluble iron ions concentration, form of iron, etc.

Figure 5 plots the measured phenol production by stepwise-reduced $\mathrm{Ni} / \mathrm{Fe}$ under different buffered conditions, with and without sample pretreatment. A stable baseline of the spectrum could be achieved by pretreatment, and reasonable phenol concentration was detected. The maximum concentration of detected phenol after $2 \mathrm{~h}$ of reaction was $490.9 \mathrm{mM}$. Therefore, $98.2 \%$ of phenol existed in aqueous phase. The only remained $1.8 \%$ could be either unreacted $4-$ chlorophenol or adsorbed phenol.

Depending on buffered condition significance of pretreatment was varied. In case of the condition buffered with $10 \mathrm{mM}$ acetate, the same pattern was obtained as was observed in the long term test, plotted in Figure 3. A significant difference of absorbance by pre-treatment was observed after $30 \mathrm{~min}$ of reaction. It revealed the necessity of pretreatment for residual iron ions removal, since the total iron concentration was measured as $218.5 \pm 28.0 \mathrm{mg} / \mathrm{L}$ in the filtered samples. This high concentration soluble iron ions was attributed to the acidic $\mathrm{pH}(3.5-4.0)$ maintained during the reaction under buffered condition. 
Contrastingly, the change of absorbance by pretreatment was negligible under un-buffered condition. High pH could be expected under un-buffered conditions, due to hydroxide produced in the reaction between nZVI and 4-chlorophenol, as described in Eq. 9. Consequently, an iron hydroxide coating could be generated in this high $\mathrm{pH}$ environment, which can prevent the loss of iron in the soluble ionic form [29]. The low concentration of soluble iron ions concentration in the filtered sample $(7.9-19.2 \mathrm{mg} / \mathrm{L})$ ensured the insignificant positive interference on the color development.

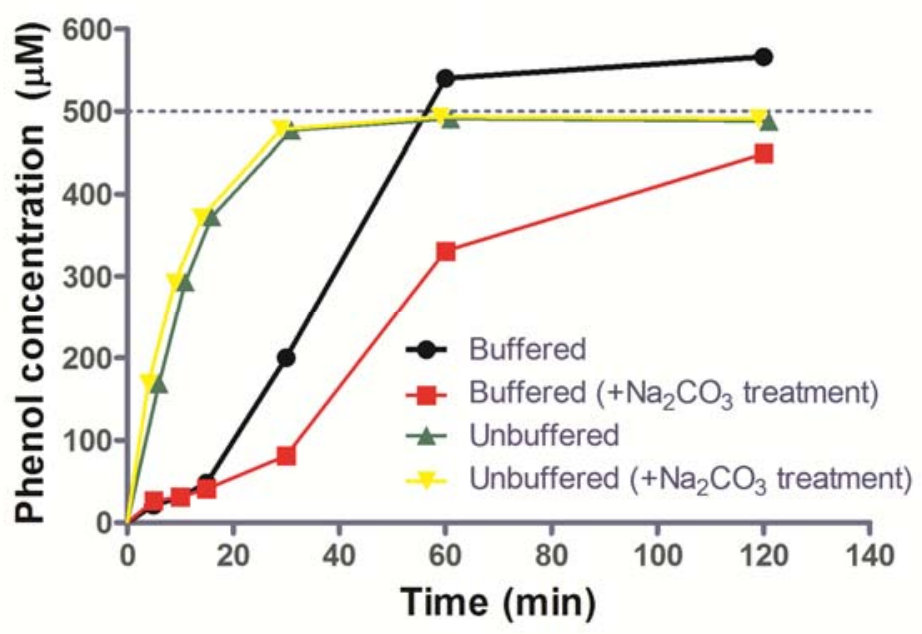

Fig. 5. Measured phenol production by Ni/Fe under different buffered condition. Dotted line indicate theoretical yield.

This suggested pretreatment scheme is strongly related with iron speciation. Since alkaline condition was provided by adding carbonate, iron would be insoluble. Moreover, the redox condition play a major role on iron speciation. When sample was taken from sealed reactor, it turned oxic condition which make more insoluble Fe(III) precipitation. By adding excess carbonate it is ensured that the $\mathrm{pH}$ becomes high enough that both $\mathrm{Fe}(\mathrm{II})$ and Fe(III) will not stay in solution. Additionally the $\mathrm{FeCO}_{3}$ quickly forms heavy crystal grains that adds weight to the fluffy Fe(III)hydroxides so they settles in a reasonable time. Since the interference caused by $\mathrm{pH}$ and residual iron can be eliminated by carbonate treatment of the sample, it is therefore suggested to use carbonate pretreatment as a standard procedure for ensuring a high $\mathrm{pH}$ and a low iron ions concentration, which is favorable for the indophenol reaction.

\section{CONCLUSION}

In this study, the modified indophenol reaction that is originally used for ammonia detection was suggested for phenol detection in the mixture of 4-chlorophenol and phenol. Since 4-chlorophenol can be reduced to phenol by nZVI and 4chlorophenol cannot be detected by the indophenol reaction, the simple colorimetric assay for reducing reactivity determination of nZVI to organically bound halogens was developed, using 4-chlorophenol as the model substrate. The suggested color assay showed superior selectivity towards phenol in the presence of 4-chlorophenol, which showed the applicability of the assay based on the suggested purpose.

The sensitivity and selectivity of the color assay for phenol detection was investigated. Being that a shift in the peak absorbance was observed at the concentration range of $100-400 \mu \mathrm{M}$, the appropriate concentration range for analysis was determined to be $0-50 \mu \mathrm{M}$ with peak absorbance of $680 \mathrm{~nm}$. The suggested color assay displayed superior selectivity towards phenol in the presence of 4-chlorophenol, which demonstrated the feasibility of the assay, as suggested.

However, the high concentration of soluble iron ions produced throughout the reaction caused a positive interference on absorbance, due to baseline increase on the spectra. Addition of $\mathrm{Na}_{2} \mathrm{CO}_{3}$ as a sample pretreatment was suggested to eliminate the effect of residual iron in the color assay. The residual iron ions in the sample were successfully removed by precipitation after 30 minutes. Additionally, experiment results revealed that the addition of $\mathrm{Na}_{2} \mathrm{CO}_{3}$ served to eliminate interference from buffers used in reactivity experiments at different $\mathrm{pHs}$.

Among several types of nZVI applied, the bimetallic Ni/Fe, produced either by co-reduction or stepwise-reduction, showed the production of phenol, indicating a promotion of reducing reactivity by nickel via production of atomic hydrogen with electrons supplied by the Fe core. Throughout this study, the 4-chlorophenol based reactivity assay using 
the modified indophenol reaction successfully determined reducing reactivity of nZVI in varied experimental conditions. Further optimization with microplate analysis will increase the simplicity and applicability of the suggested method for testing nZVI reactivity.

\section{Acknowledgement}

Yuhoon Hwang acknowledges funding for this study through Basic Science Research Program through the National Research Foundation of Korea (NRF) funded by the Ministry of Education, Science and Technology (2013R1A6A3A03026864) and Individual postdoctoral grants through the Danish Council for Independent Research (DFF-4005-00393). Paul D. Mines and Henrik R. Andersen recognize funding from the Technical University of Denmark (DTU) for this work through a strategic research initiative for cooperation with KAIST. The authors recognize input to the idea development from Professor Hans Mosbæk.

\section{Reference}

[1] R.A. Crane, T.B. Scott, J. Hazard. Mater. 211-212 (2012) 112-125.

[2] C.B. Wang, W.X. Zhang, Environ. Sci. Technol. 31 (1997) 2154-2156.

[3] N. Saleh, K. Sirk, Y. Liu, T. Phenrat, B. Dufour, K. Matyjaszewski, R.D. Tilton, G.V. Lowry, Environ. Eng. Sci. 24 (2007) 45-57.

[4] H.-J. Kim, T. Phenrat, R.D. Tilton, G.V. Lowry, Environ. Sci. Technol. 43 (2009) 3824-3830.

[5] H. Dong, I.M. Lo, Water Res. 47 (2013) 419-427.

[6] A. Tiraferri, K.L. Chen, R. Sethi, M. Elimelech, J. Colloid. Interf. Sci. 324 (2008) 71-79.

[7] N. Sakulchaicharoen, D.M. O'Carroll, J.E. Herrera, J. Contam. Hydrol. 118 (2010) 117-127.

[8] W.-h. Zhang, X. Quan, Z.-y. Zhang, J. of Environ. Sci. 19 (2007) 362-366.

[9] Y. Liu, G.V. Lowry, Environ. Sci. Technol. 40 (2006) 6085-6090.

[10] R.J. Barnes, O. Riba, M.N. Gardner, T.B. Scott, S.A. Jackman, I.P. Thompson, Chemosphere 79 (2010) $448-$

454

[11] Y. Liu, S.A. Majetich, R.D. Tilton, D.S. Sholl, G.V. Lowry, Environ. Sci. Technol. 39 (2005) 1338-1345.

[12] S. Bae, W. Lee, Environ. Sci. Technol. 48 (2014) 2368-2376.

[13] R. Cheng, J.-l. Wang, W.-x. Zhang, J. Hazard. Mater. 144 (2007) 334-339.

[14] P.J. Dorathi, P. Kandasamy, J. Environ. Sci. 24 (2012) 765-773.

[15] Y. Li, Y. Zhang, J. Li, G. Sheng, X. Zheng, Chemosphere 92 (2013) 368-374.

[16] P.L. Searle, Analyst 109 (1984) 549-568.

[17] A. Afkhami, R. Norooz-Asl, J. Brazil. Chem. Soc. 19 (2008) 1546-1552.

[18] Y. Hwang, Y.-C. Lee, P.D. Mines, Y.S. Huh, H.R. Andersen, Appl. Catal. B: Environ. 147 (2014) $748-755$.

[19] Y.H. Liou, S.-L. Lo, C.-J. Lin, W.H. Kuan, S.C. Weng, J. Hazard. Mater. 127 (2005) 102-110.

[20] F. Alonso, I.P. Beletskaya, M. Yus, Chem. Rev. 102 (2002) 4009-4091.

[21] A. Ghauch, A. Tuqan, Chemosphere 73 (2008) 751-759.

[22] Y.H. Hwang, D.G. Kim, H.S. Shin, J. Hazard. Mater. 185 (2011) 1513-1521.

[23] W.-J. Liu, T.-T. Qian, H. Jiang, Chem. Eng. J. 236 (2014) 448-463.

[24] B.P. Chaplin, M. Reinhard, W.F. Schneider, C. Schuth, J.R. Shapley, T.J. Strathmann, C.J. Werth, Environ. Sci. Technol. 46 (2012) 3655-3670.

[25] D.M. Cwiertny, S.J. Bransfield, K.J. Livi, D.H. Fairbrother, A.L. Robertst, Environ. Sci. Technol. 40 (2006) 6837-6843.

[26] K.-F. Chen, S. Li, W.-x. Zhang, Chem. Eng. J. 170 (2011) 562-567.

[27] J.A. Russell, J. Biol. Chem. 156 (1944) 457-462.

[28] C.J. Lin, S.L. Lo, Y.H. Liou, J. Hazard. Mater. 116 (2004) 219-228.

[29] G.C.C. Yang, H.-L. Lee, Water Res. 39 (2005) 884-894. 
Post Print: This is a Supporting Information of the manuscript "Simple colorimetric assay for dehalogenation reactivity of nanoscale zero-valent iron using 4-chlorophenol." accepted for publication on the 22/10 2014. The publishers' version is printed in Applied Catalysis B: Environmental and is available at http://dx.doi.org/10.1016/j.apcatb.2014.10.059

\title{
Supplementary Information
}

\section{Simple colorimetric assay for dehalogenation reactivity of nanoscale zero-valent iron using 4-chlorophenol}

\author{
Yuhoon Hwang ${ }^{1}$, Paul D. Mines ${ }^{1}$, Mogens H. Jakobsen ${ }^{2}$, Henrik R. Andersen ${ }^{1 *}$ \\ ${ }^{1}$ Department of Environmental Engineering, Technical University of Denmark, Miljøvej, B113, DK-2800 Kgs. Lyngby, \\ Denmark \\ ${ }^{2}$ Department of Micro- and Nanotechnology, Technical University of Denmark, Ørsteds Plads, B 345E, DK-2800 Kgs. \\ Lyngby, Denmark
}

\footnotetext{
* Corresponding author

Henrik R. Andersen

E-mail:hran@env.dtu.dk

Tel: +45-4525-1583

Fax: +45-4593-2850
} 


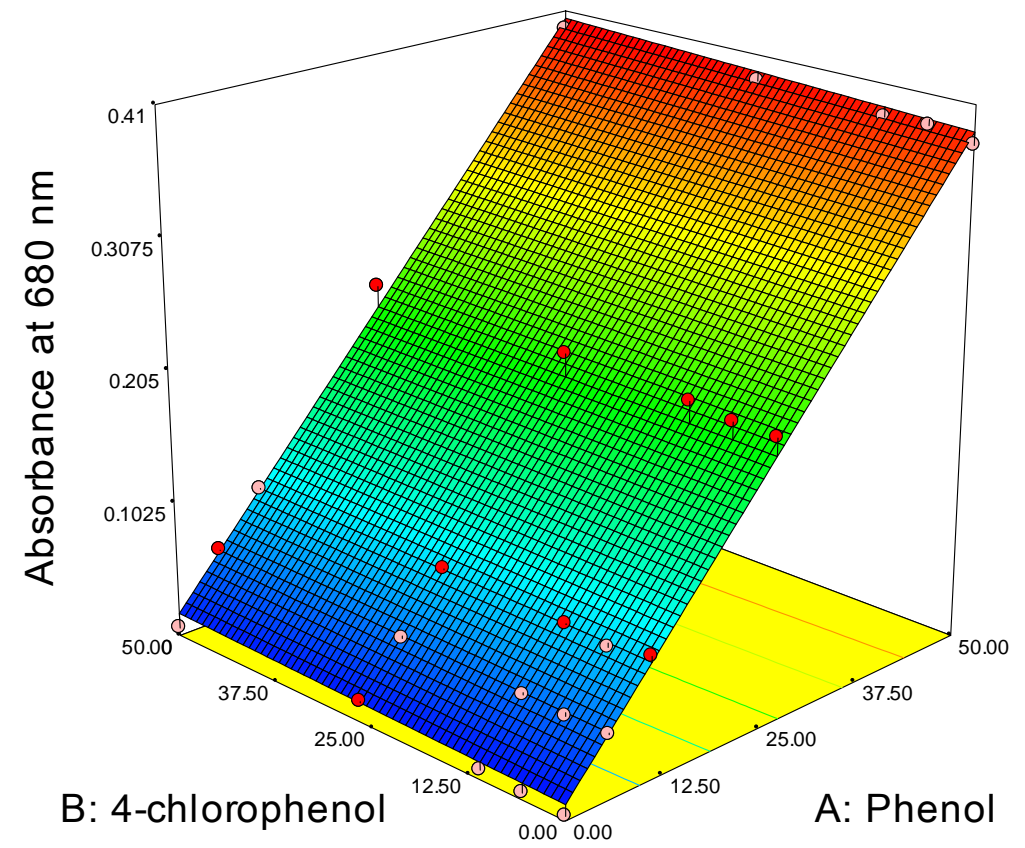

Figure S1. Response surface of absorbance at $680 \mathrm{~nm}$ for mixture of phenol and 4chlorophenol after reaction with $\mathrm{NH}_{2} \mathrm{Cl}$. 


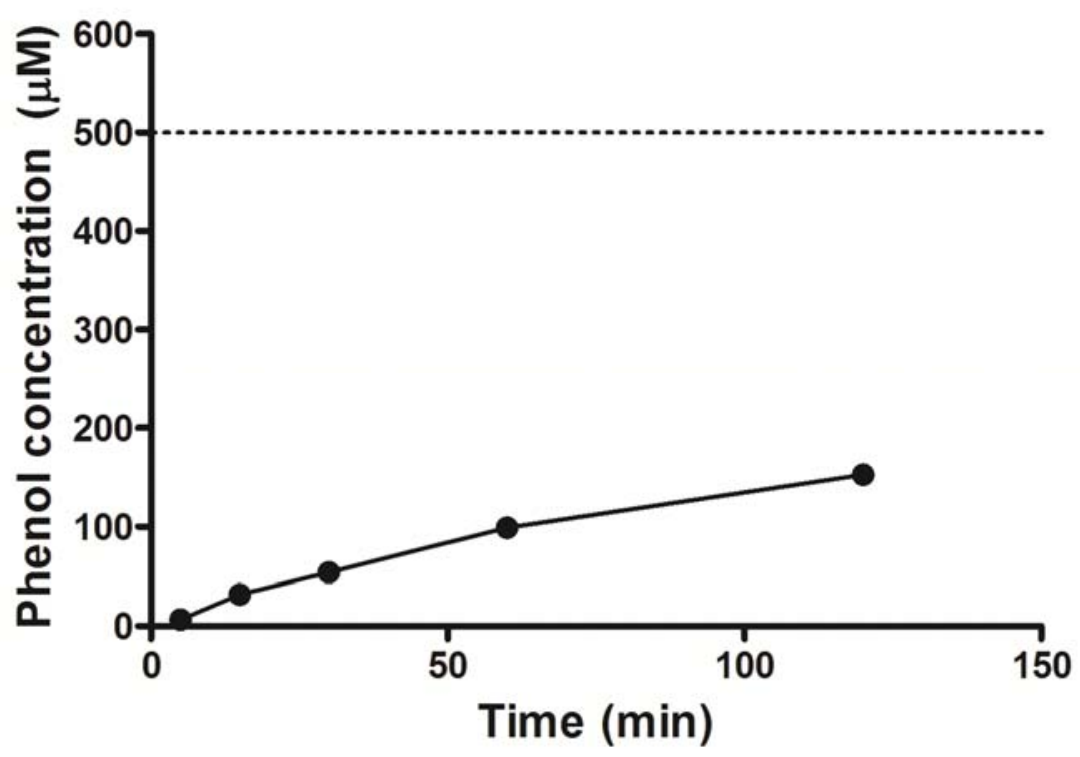

Figure S2. Produced phenol concentration by co-reduced Ni/Fe bimetallic particles. Dotted line indicate theoretical yield 
(a)

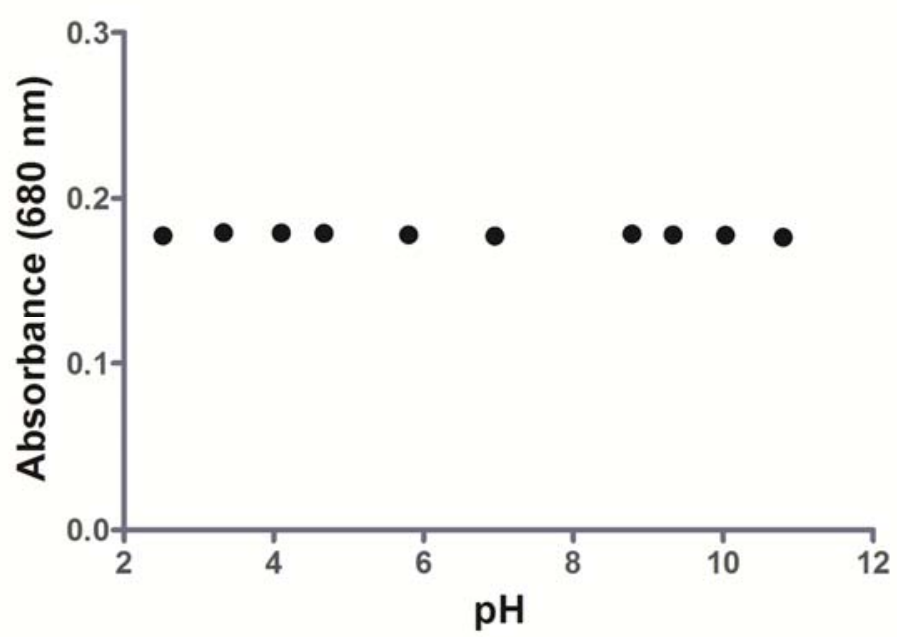

(b)

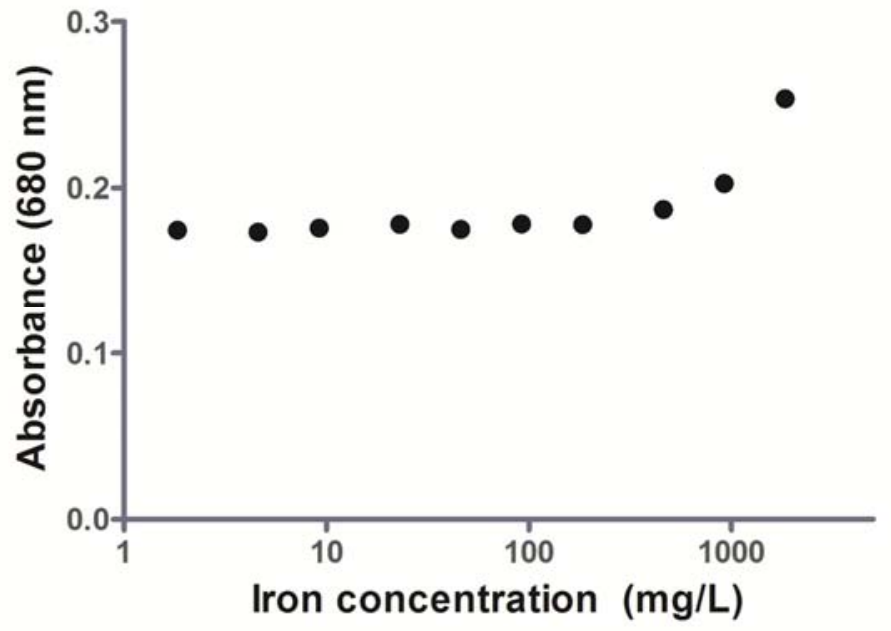

Figure S3. Effect of $\mathrm{pH}$ and residual iron ions concentration on phenol determination (added phenol concentration $=20 \mu \mathrm{M}$ ) 


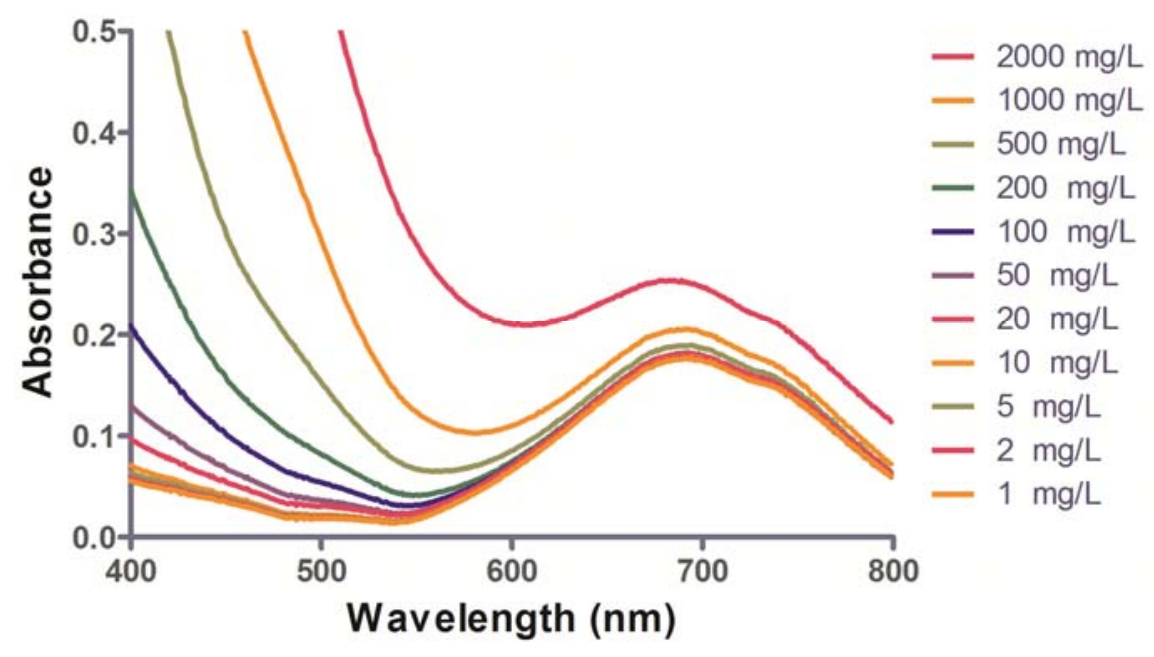

Figure S4. Absorption spectra of color production with soluble iron ions (added phenol concentration $=20 \mu \mathrm{M}$ ) 